\title{
Energy Efficient Intelligent Household LED Lighting System Based On Daylight Illumination
}

\author{
Kranti Asolkar ${ }^{1}$, Dr. S.S. Ardhapurkar ${ }^{2}$ \\ ${ }^{1}$ Electronics and Telecommunication Engineering Department, Marathwada Institute of Technology, \\ Aurangabad-431001, India \\ ${ }^{2}$ Electronics and Telecommunication Engineering Department, Marathwada Institute of Technology, \\ Aurangabad-431001, India \\ ${ }^{1}$ 2kranti.asolk@gmail.com \\ 2vaidyshubha21@gmail.com
}

\begin{abstract}
In today's life it becomes very necessary to save energy. Environmental problems such as climate change and global warming are various issues caused by the excessive use of energy. Electrical energy in terms of light accounts 20 percent of word's total energy consumption. The paper focuses on energy efficient indoor LED light control system based on user's state and surroundings. The designed system uses control unit, sensors, LED driver and wireless sensor technology. Dimming is possible by using PWM method. The proposed system measures total energy consumption to verify the performance.

Keyword - Light emitting diode, Lighting control system, Dimming control, Daylight illumination, Wireless technology
\end{abstract}

\section{INTRODUCTION}

In day-to-day life, more power consumption is caused due to the use of consumer electronics. In residential buildings lighting systems are still designed according to the old standards. Implementation of latest technology is hardly used. As more and more home appliances and consumer electronics are installed, residential energy consumption tends to grow rapidly. A large number of home devices increase power consumption in two aspects, standby power and normal operation power. Those two kinds of power consumption are proportional to the number of home devices. As a result, operational cost in home area is also increasing.

In traditional lighting control system, unnecessary power consumption is caused by two main things:

- On/off switch

- $\quad$ Light source used

The lights generally used for illumination are the "incandescent lamp" and "fluorescent lamp”. It consumes more electricity. In recent years uses of LED lights has been more increasing. The LED lights are the most practical answer to decrease power consumption in residential and commercial buildings. As compare to other light sources, LED lights has a better performance in lumen/watt, electricity saving and lifetime aspects. As shown in table 1 , different lighting sources are compared.

TABLE 1. Comparison of lighting sources

\begin{tabular}{|l|l|l|l|}
\hline \multirow{2}{*}{} & \multicolumn{3}{|c|}{ Commonly used lighting sources } \\
\cline { 2 - 4 } & Incandescent lamp & Fluorescent lamp & LED light \\
\hline Efficacy & $12-24$ lumen/watt & $50-70$ lumen/watt & $50-200$ lumen/watt \\
\hline Power consumption & $100 \mathrm{~W}$ & $25 \mathrm{~W}$ & $0.03-0.06 \mathrm{~W}$ \\
\hline Lifetime & 3000 hours & $3000-6000$ hours & $10000-50000$ hours \\
\hline Driver & AC power & AC power & DC power \\
\hline Size & Large & Large & Small \\
\hline
\end{tabular}

In recent years, modern lighting control system introduce in the market. The proposed system is based on various sensors and communication module. The intelligent light control system can reduce the power consumption by automatically controlling the illumination intensity considering user's state and surroundings. 


\section{RELATED WORK}

There are many methods evolved on lighting control system. Pan et al (1) proposed a wireless sensor network based intelligent light control system considering user activities and profiles. The paper focuses on illumination requirement of a user and proposes close loop device control algorithm to adjust illumination levels of a lighting devices and to save energy.

Hung et al (2) proposed halftone control method to control lights automatically. This system recognizes brightness of surrounding and according to that shows the dimming of low power LED lights.

Uhm et al (3) proposed power aware LED light enabler system. It introduces location aware adaptive middleware and context aware user pattern system which uses light sensors, motion sensors and network interfaces. By using light enabler system up to 58\% energy saving can be achieved.

Han et al (4) proposed more efficient home energy management system to decrease power consumption in home area. The system focuses on to reduce standby power of a home device. The system uses zigbee communication and infrared remote controls to control lights and other home devices.

Outeirino et al (5) proposed building lighting automation system through the integration of digital addressable lighting interfaces devices with the use of wireless sensor networks.

Byun et al (6) proposed energy efficient intelligent household LED lighting system using multi sensors and wireless communication technology. To adjust brightness of light minimum light intensity control algorithm has been developed. The system is implemented on test bed and reduces total power consumption up to $21.9 \%$.

Parimala et al (7) proposed smart home lighting system using Wireless sensor network and Ethernet. The system uses motion sensors, light sensors, controller, energy meter and Ethernet as a network interface.

Mahalakshmi et al (8) proposed home LED lighting system using pulse width modulation technique and analysis of load priority. It introduces two algorithms, illumination decision algorithm and load priority algorithm. Energy consumption of the device is achieved up to $43.695 \%$.

Kaleem et al (8) proposed zigbee based energy efficient outdoor light monitoring and control architecture using embedded system. The system includes occupancy sensors, power metering IC, controller and zigbee wireless network. The system saves around $70.8 \%$ energy for the outdoor street lights.

\section{III.OVERVIEW OF INDOOR LIGHTING SYSTEM}

We propose energy efficient indoor LED lighting system using various sensors and wireless communication technology. Fig. 1 shows an overview of indoor lighting system.

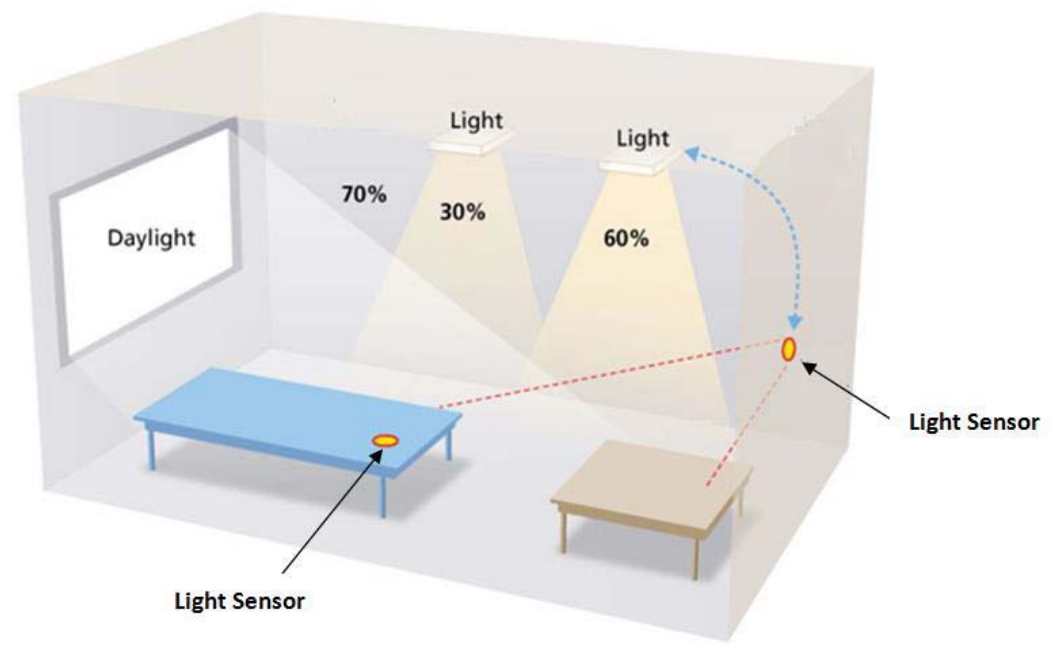

Fig. 1. Overview of indoor lighting system

In indoor lighting system, light required for various tasks is different. Daylight illumination is very important factor for indoor lighting system. With respect to the daylight illumination level, it becomes possible to adjust the light intensity of a room. If natural light present in room is suitable for normal working tasks then there is no need to turn on lights. But light present in room is not sufficient in that condition we have to turn on lights. In traditional lighting system, there is only a normal switch to turn on/off the lights. Energy consumption is more in that case. In proposed LED lighting system dimming is possible, hence as per the natural light present in a room in a whole day it shows possible dimming and lights energy consumption is less. Following table shows the light intensity in a lumen required for particular task in a home. 
TABLE 2. Residential Illumination Recommendation for General Lighting and Specific Visual Tasks

\begin{tabular}{|l|l|}
\hline \multicolumn{1}{|c|}{ Room Type } & \multicolumn{1}{c|}{ Light Level in Lux } \\
\hline Bedroom & $200-300$ \\
\hline Dining hall & $200-300$ \\
\hline General hall & $300-500$ \\
\hline Study room & $300-500$ \\
\hline Kitchen & $300-750$ \\
\hline Washroom & $100-300$ \\
\hline Stairway & $50-100$ \\
\hline
\end{tabular}

Theoretically, light intensity (illumination) can be calculated by using formula:

$$
I=\frac{L_{I} C_{u} L_{L F}}{A_{I}}
$$

Where,

$\mathrm{I}=$ illumination (Lux, lumen $\left./ \mathrm{m}^{2}\right)$

$\mathrm{L}_{\mathrm{I}}=$ lumen per lamp (lumen)

$\mathrm{C}_{\mathrm{u}}=$ coefficient of utilization

$\mathrm{L}_{\mathrm{LF}}=$ light loss factor

$\mathrm{A}_{\mathrm{I}}=$ area per lamp $\left(\mathrm{m}^{2}\right)$

\section{IV.Proposed ENERgy EFFICIENT Led Lighting SySTEM}

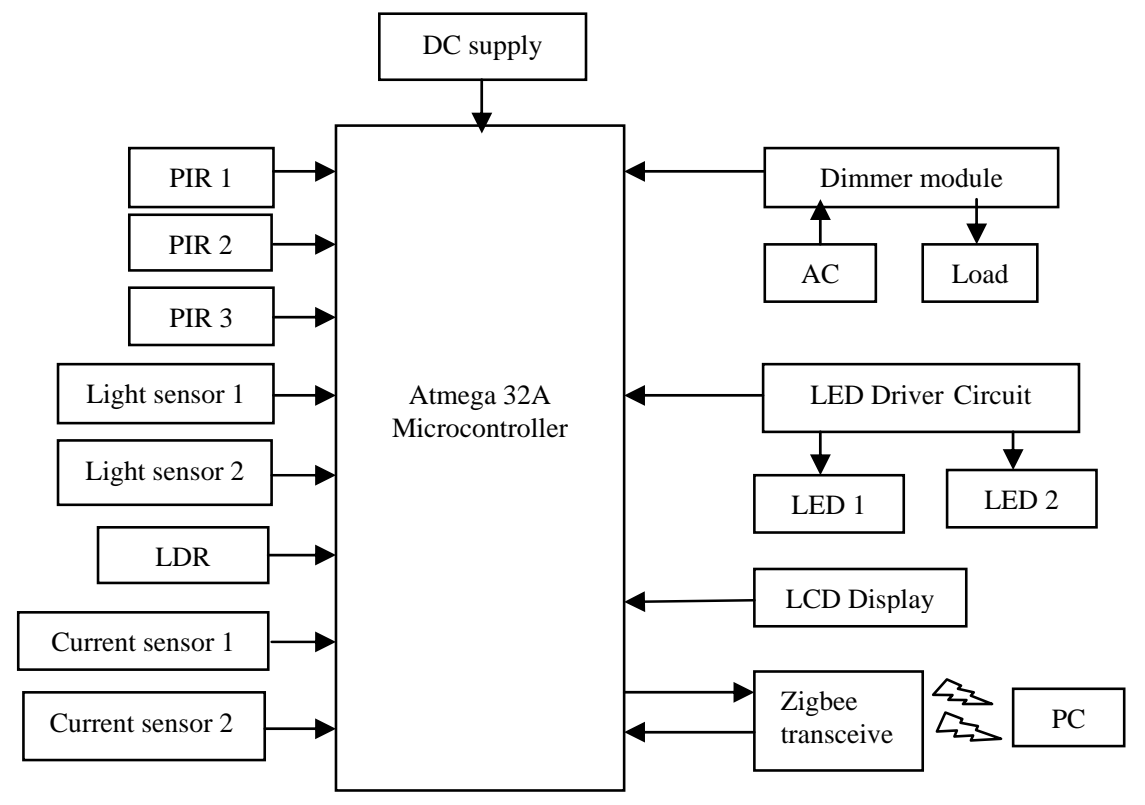

Fig. 2. Block diagram of the proposed system

In this paper we designed energy efficient indoor LED lighting system based on:

- Energy savings LED luminaries

- Motion sensors to detect presence of human body

- Brightness sensors to detect illumination intensity of surroundings

The LED light control system consists of various modules: motion sensor, light sensor and current sensor, controller unit, LED driver, LED light source, dimmer module, LCD display and zigbee transceiver as shown in fig.2. When power supply is on, PIR sensor first check the presence of a person in a room and then decision has been taken by the controller to turn the lights on or off. At the same time light sensor continuously monitors the light intensity of a surrounding connected to the controller and based on that intensity value Atmega 32A controller takes decision to control or dim the lights and turn lights on or off. The status of that room can be continuously monitors on the PC by using GUI through zigbee transceiver. Dimmer module used in the system, it requires AC supply. It shows dimming of a bulb. 
The detailed information related to the main components is explained below:

\section{A. Hardware Description:}

\section{Atmega 32A microcontroller unit:}

The Atmega 32A is the heart of the proposed system. Input sensors like PIR sensor and light sensor are connected to the input of the input pins of a controller unit. So all the information is send to the controller unit with respect to the situation. If any person present in a room and surrounding light in that room is lower or higher than the threshold value set then controller gets activated to give the proper output at the end.

Microcontroller handles all the information flow among sensors and drivers, and also generate pulse width modulation signal for dimming the LED lights.

\section{PIR Sensor:}

PIR sensor is a motion detection sensor compiles with microcontroller or DC loads. When there is human body present in a room, it detects the motion and output pin goes high otherwise low. Its detecting range is about 7 meters, 180 degree detection angle and operating voltage is 3 to $9 \mathrm{~V}$ DC.

\section{BH1750 light sensor:}

Light sensors BH1750FVI are connected to the microcontroller through I2C interface which observe the light intensity status in Lux. These light sensors measure the light intensity in the range 0-65535. This sensor measures accurate light intensity of a LED lights as per the requirement of brightness.

LDR sensor:

It is a light dependent resistor or photo resistor which is a passive electronic component, basically a resistor which has a resistance that varies depending of the light intensity.LDR connected to the controller through ADC interface. Operating voltage requires is $5 \mathrm{~V}$ Dc.

\section{Current sensor:}

The current sensor ACS714 is used to measure the current value of a LED lights. This highly accurate current sensor is connected to the analog pins of a controller. It is connected to the load i.e. LED lights directly and needs only single $5 \mathrm{~V}$ power supply. The current sensor measures the current flow in the LED lights, which is helpful to calculate the power required to the lights. The current sensitivity of the sensor is $0.185 \mathrm{~V} / \mathrm{A}$.

\section{Dimmer module:}

Dimmer module is used for dimming of a resistive load. The input can be simple 4 bit binary signal from microcontroller. It requires control input voltage $5 \mathrm{~V}$ dc and $\mathrm{AC}$ input $80 \mathrm{~V}$ to $250 \mathrm{~V}$ AC. The alternating current (AC) phase control method is used to control the intensity of a lamp. By using dimmer module the load i.e. bulb shows proper dimming of a light.

\section{LED lamp driver:}

The simple driver circuit is made having TIP122 resistor with $1 \mathrm{~K}$ resistor at the base of terminal. It is a NPN transistor simply acts as a switch to control the power of a LED lights. The LED lamp driver is used to regulate the power of a LED light source.

Zigbee Transceiver:

RF CC2500 modem is a transceiver module which provides easy to use RF communication at 2.4GHz. It can be used to transmit and receive data at multiple baud rates from any standard CMOS/TTL source. This module is direct line in replacement for the serial communication and no extra hardware and code required to turn on wired communication into wireless one. It operates in a half duplex mode that is providing communication in both directions but only one direction at a time.

In zigbee transceiver section part, $\mathrm{Tx}$ and $\mathrm{Rx}$ pins of a modem is connected to the $\mathrm{Rx}$ and $\mathrm{Tx}$ pins of a controller respectively. The information of sensors is transfer wirelessly to the PC unit. Hence it can be easy to monitor the status of lights with the help of GUI. Zigbee typically operate in the range up to 30 meters and working voltage is $5 \mathrm{~V}$ DC.

\section{B. Software Description:}

The software use to develop the programming for the system is mikroC PRO for AVR. The mikroC PRO for AVR is a full-featured ANSI C compiler for AVR devices from Atmel ${ }^{\circledR}$. It is the best solution for developing code for AVR devices. It features intuitive IDE, powerful compiler with advanced SSA optimizations, lots of hardware and software libraries, and additional tools that will help you in the work. Compiler comes with comprehensive Help file and lots of ready-to-use examples designed to get started. 


\section{TeSt CASE IMPLEMENTATION AND Discussion}

The system is designed to improve the traditional wired indoor lighting system with the energy efficient LED lighting system. The proposed prototype has been tasted under indoor scenarios to verify its validity, functionality and performance in the real life conditions. The system is installed in rainy season when weather is cloudy. In such condition light required is more in home area. We are using 20W LED SMD light in the system. Energy Consumption per month can be calculated by using formula,

$\frac{E_{\text {consume }}(K W H)}{\text { month }}=\left(\frac{\text { total wattage of luminaries }}{1000}\right) \times$ no. of lights installed $\times h /$ day $\times$ days $\times$ month

From table 3 the result clearly indicated that conventional system conventional system i.e. the system without having any smart feature consumes $52.8 \mathrm{KWH} /$ month energy while energy efficient light system consumes $25.8 \mathrm{KWH} /$ month energy. Therefore, total energy saved per month

$$
\begin{gathered}
=\frac{52.8-25.8}{52.8} \times 100 \% \\
=51.14 \%
\end{gathered}
$$

Electricity cost can be calculated by using formula,

$$
\text { Electricity cost }=\text { Electricity rate } \times K W H
$$

In electricity bill, electricity rate is different in different region. Average electricity rate is $4.16 \mathrm{Rs}$. /KWH in MSEB region.

Therefore, electricity cost for conventional system $=219.6$ Rs. $/$ month

Electricity cost for energy efficient lighting system $=107.3$ Rs. $/$ month

\begin{tabular}{|c|c|c|c|c|c|c|c|c|c|c|}
\hline \multirow{2}{*}{$\begin{array}{c}\text { Room } \\
\text { Type }\end{array}$} & \multirow{2}{*}{$\begin{array}{c}\text { Dimension } \\
(\mathrm{Ft} \times \mathrm{Ft})\end{array}$} & \multirow{2}{*}{$\begin{array}{l}\text { Lumen } \\
\text { required } \\
\text { for area } \\
\text { sq. meter }\end{array}$} & \multicolumn{4}{|c|}{ Conventional system } & \multicolumn{4}{|c|}{ Proposed system } \\
\hline & & & $\begin{array}{c}\text { CFL } \\
\text { lamp } \\
\text { installed }\end{array}$ & $\begin{array}{c}\text { Rating } \\
\text { of lamp } \\
\text { unit (W) }\end{array}$ & $\begin{array}{l}\text { Operating } \\
\text { hours per } \\
\text { day }\end{array}$ & $\begin{array}{c}\text { Energy } \\
\text { consumption/ } \\
\text { month } \\
\text { (KWH/ } \\
\text { month) }\end{array}$ & $\begin{array}{c}\text { LED } \\
\text { lamp } \\
\text { installed }\end{array}$ & $\begin{array}{c}\text { Rating } \\
\text { of lamp } \\
\text { unit } \\
\text { (W) }\end{array}$ & $\begin{array}{l}\text { Operatin } \\
\text { g hours } \\
\text { per day } \\
\text { (Average) }\end{array}$ & $\begin{array}{c}\text { Energy } \\
\text { consumption } \\
\text { /month } \\
\text { (KWH/ } \\
\text { month) }\end{array}$ \\
\hline Hall & $16 \times 17$ & 8000 & 6 & 20 & 8 & 28.8 & 4 & 20 & 6 & 14.4 \\
\hline Kitchen & $10 \times 10$ & 4650 & 4 & 20 & 7 & 16.8 & 3 & 20 & 5 & 9 \\
\hline
\end{tabular}

That is total energy saving cost is Rs.112.3

TABLE 3. Energy Consumption Per Month (Conventional Vs Proposed System)

In proposed system, the calculated energy consumption is due to the usage of LED lamps, dimming feature of LED lamps and by using the occupancy sensor. Therefore, the proposed lighting control system reduces energy consumption up to approximately $51.14 \%$. The bar chart plotted for conventional and proposed system in figure 3 . During summer, when sun is full bright these features of a lighting system again reduce the average operating time of the proposed system. So again it reduces energy consumption of lights.

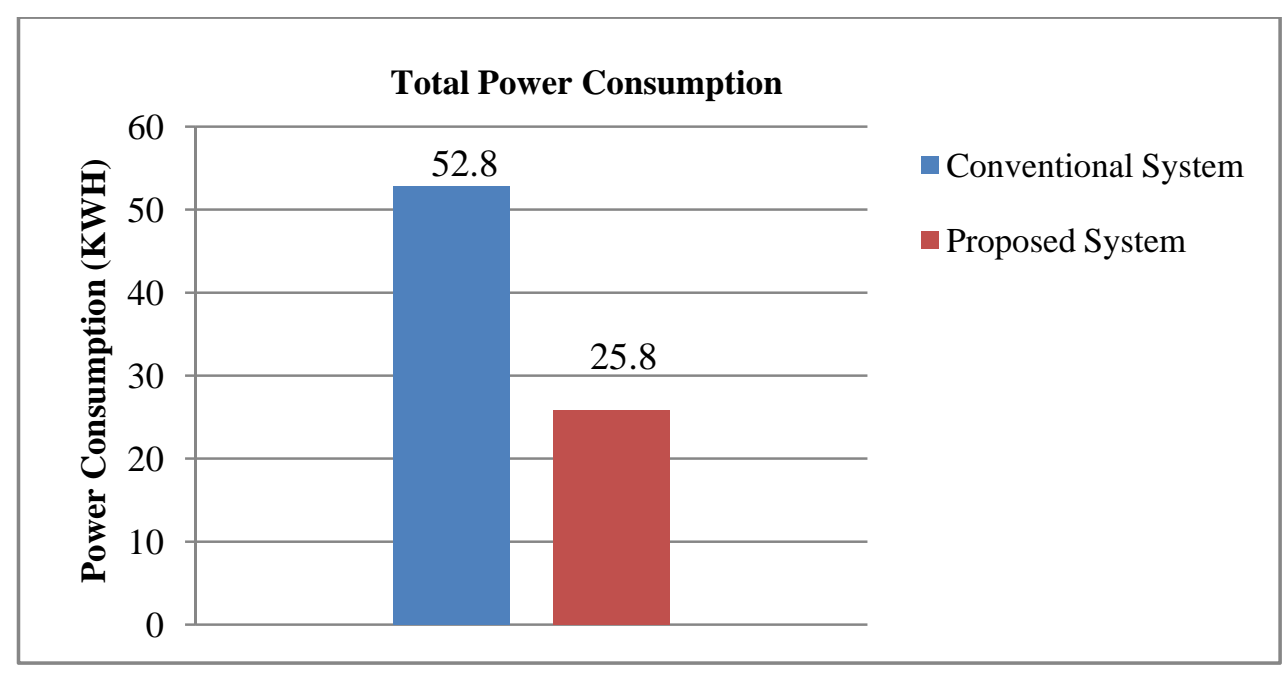

Fig. 3. Energy consumption comparison using conventional and proposed energy efficient system 
The line chart given below shows dimming steps of LED light source considering user’s surroundings.

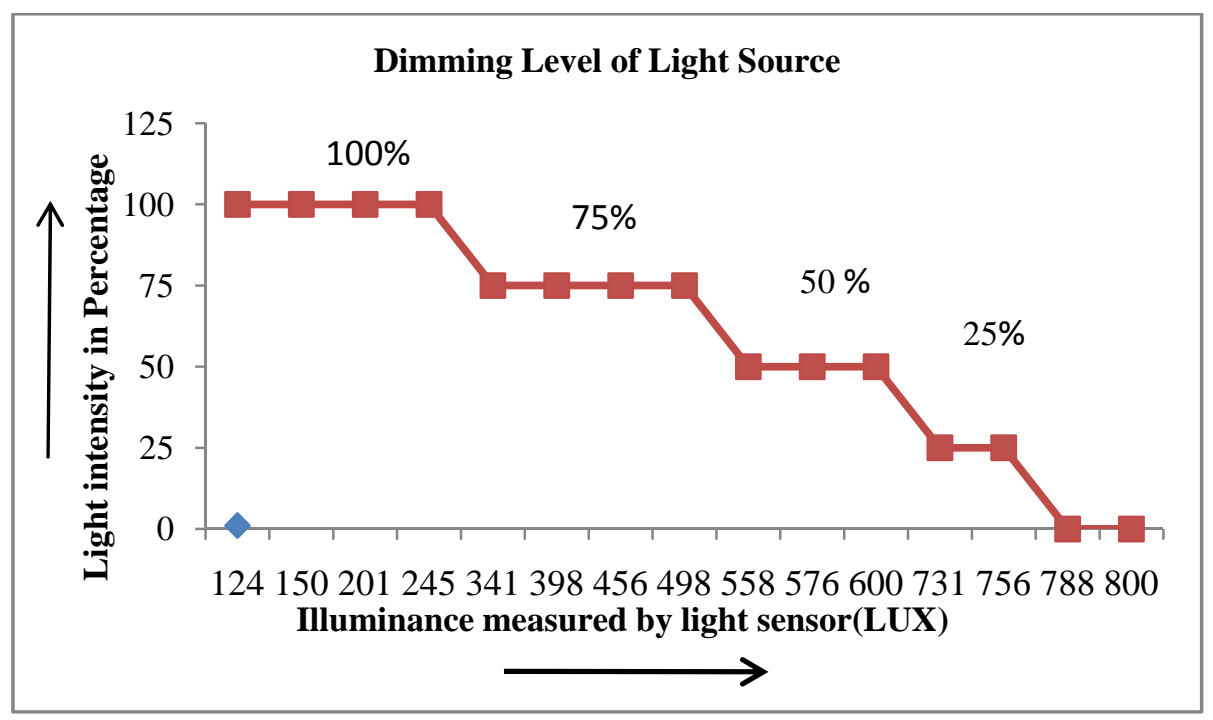

Fig. 4. Illuminance measured by light sensor vs. light source intensity (\%)

\section{VI.CONCLUSION}

We proposed cost effective and energy efficient LED lighting control system for indoor environment. With the help of daylight illumination, the proposed system take care of minimum light required in a room so minimum power can be required and energy can be saved up to 52.6\%. The dimming can be achieved by using PWM method. In addition, the designed system can monitor the status of a room on monitoring device using GUI. Furthermore, the proposed system is suitable for conference room and teaching room with slight modification where the need of light required is different. So the designed system is cost effective, flexible, extendable and fully adaptable to the user need.

\section{REFERENCES}

[1] M.Pan, L.Yeh,, Y.chen,Y.Lin and Y.Tseng, "A WSN-based intelligent light control system considering user activities and profiles,”IEEEsensors journal, vol.8, no.10, October 2008.

[2] C.Huang and Y.W. Bai, "Halftone control method in white light LEDs by using an embedded remote controller with zigbeecommunication,” IEEE canadian conference on Electrical and Computer Engineering,Calgary,Alberta,Canada,May 2-5,2010.

[3] Y. Uhm and I.Hong, "Design and implementation of power aware LED light enabler with location aware adaptive middleware and context aware user pattern,” IEEE transactions on consumer electronics, vol.56.no.1, February 2010.

[4] J.Han and C.Choi, "More efficient home energy management system based on zigbee communication and infrared remote controls," IEEE transactions on consumer electronics, vol.57,no.1,February 2011.

[5] F.Outeirino, J.Arias, F.Perez, A.Castro and A.Munoz, "Building lighting automation through the integration of DALI with wireless sensor networks,”IEEE transaction on consumer electronics, vol. 58, no. 1, February 2012.

[6] J.Byun, I.Hong, B.Lee and S.Park, "Intelligent household LED lighting system considering energy efficiency and user satisfaction," IEEE transaction on consumer electronics, vol.59, no. 1, February 2013.

[7] A.Parimala and B.Manoharbabu, "Smart home lighting system for high efficiency by using WSN and ethernet," International journal of eminent engineering technologies, vol.1, issue 3, November 2014.

[8] S.Mahalakshmi and C. Sasikumar, "Implementation of home lighting system using pulse width modulation technique and analysis of load priority,” International journal of emerging technology and innovative engineering, vol.1, issue 3, March 2015.

[9] Z. Kaleem, T. Yoon and C.Lee, "Energy efficient outdoor light monitoring and control architecture using embedded system," IEEE embedded system letters, vol. 8, no.1, March 2016.

[10] https://www.noao.edu/education/QLTkit/../Safety/LightLevels_outdoor+indoor.pdf

[11] https://www.archtoolbox.com/materials-systems/electrical/recommended-lighting-levels-in-buildings.html

[12] http://www.pfisterenergy.com/lighting-controls/ 


\section{AUTHOR PROFILE}

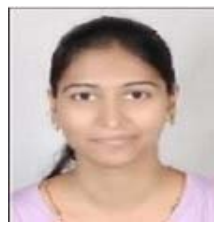

Kranti Asolkar received her B.E., in Electronics and telecommunication engineering from Shri Sant Gajanan Maharaj College of Engineering, Shegaon, Maharashtra India, in 2014 and pursing M.E., in embedded system from Marathwada Institute of Technology, Aurangabad, India. Her current research interests include embedded system, energy saving system and power management.

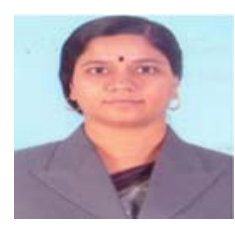

Dr. S.S. Ardhapurkar received the Bachlor's degree (1987) and the Master of Engineering degree (1994) in Electronics from Amaravati University respectively. She completed Ph.D. in Biomedical Engineering field on "Studies of ECG Classification using Signal Processsing Techniques” from S.G.G.S. Institute of Engineering and Technology, Nanded, Maharashtra, India. She has 26 years of teaching experience and currently working as a Professor in Electronics and Telecommunication Engineering department at Marathwada Institute of Technology at Aurangabad, Maharashtra, India. She has published 10 research papers in Journals and international conferences. Her research interests include Signal processing, VLSI Communication and Neural Networks .She is member of IEEE. 